\title{
The Evaluation of Photogrammetry-Based DSM from Low- Cost UAV by LiDAR-Based DSM
}

\author{
Mateo Gašparović ${ }^{1}$, Ante Seletković2 ${ }^{2}$ Alen Berta ${ }^{3}$, Ivan Balenović ${ }^{4 *}$
}

(1) University of Zagreb, Faculty of Geodesy, Chair of Photogrammetry and Remote Sensing, Kačićeva 26, HR-10000 Zagreb, Croatia; (2) University of Zagreb, Faculty of Forestry, Department of Forest Inventory and Management, Svetošimunska 25, HR-10000 Zagreb, Croatia; (3) Oikon Ltd. Institute of Applied Ecology, Department of Natural Resources Management, Trg Senjskih Uskoka 1-2, HR-10000 Zagreb, Croatia; (4) Croatian Forest Research Institute, Division for Forest Management and Forestry Economics, Trnjanska cesta 35, HR-10000 Zagreb, Croatia

* Correspondence: e-mail: ivanb@sumins.hr
Citation: GAŠPAROVIĆ M, SELETKOVIĆ A, BERTA A, BALENOVIĆ I 2017 The Evaluation of Photogrammetry-Based DSM from LowCost UAV by LiDAR-Based DSM. South-east Eur for 8 (2): 117-125. DOI: https://doi. org/10.15177/seefor.17-16

Received: 14 Oct 2017; Revised: 25 Nov 2017; Accepted: 29 Nov 2017; Published online: 11 Dec 2017

\begin{abstract}
Background and Purpose: Unmanned aerial vehicles (UAVs) are flexible to solve various surveying tasks which make them useful in many disciplines, including forestry. The main goal of this research is to evaluate the quality of photogrammetrybased digital surface model (DSM) from low-cost UAV's images collected in non-optimal weather (windy and cloudy weather) and environmental (inaccessibility for regular spatial distribution of ground control points - GCPs) conditions.

Materials and Methods: The UAV-based DSMs without $\left(D_{S M}\right)$ and with using GCPs (DSM P.GCP $_{\text {. }}$ ) were generated. The vertical agreement assessment of the UAV-based DSMs was conducted by comparing elevations of 60 checkpoints of a regular $100 \mathrm{~m}$ sampling grid obtained from LiDAR-based DSM (DSM) with the elevations of planimetrically corresponding points obtained from $D_{S M_{p}}$ and DSM $M_{p-G C P}$. Due to the non-normal distribution of residuals (vertical differences between UAV- and LiDAR-based DSMs), a vertical agreement was assessed by using robust measures: median, normalised median absolute deviation (NMAD), $68.3 \%$ quantile and $95 \%$ quantile.

Results: As expected, DSM $M_{P . G C P}$ shows higher accuracy, i.e. higher vertical agreement with $D_{S} M_{L}$ than $D_{S M}$. The median, NMAD, 68.3\% quantile, 95\% quantile and RMSE* (without outliers) values for DSM are $2.23 \mathrm{~m}, 3.22 \mathrm{~m}, 4.34 \mathrm{~m}, 15.04 \mathrm{~m}$ and $5.10 \mathrm{~m}$, respectively, whereas for DSM P.GCP $_{\text {amount to }}-1.33 \mathrm{~m}, 2.77 \mathrm{~m}, 0.11 \mathrm{~m}, 8.15 \mathrm{~m}$ and $3.54 \mathrm{~m}$, respectively.

Conclusions: The obtained results confirmed great potential of images obtained by low-cost UAV for forestry applications, even if they are surveyed in non-optimal weather and environmental conditions. This could be of importance for cases when urgent UAV surveys are needed (e.g. detection and estimation of forest damage) which do not allow careful and longer survey planning. The vertical agreement assessment of UAV-based DSMs with LiDAR-based DSM confirmed the importance of GCPs for image orientation and DSM generation. Namely, a considerable improvement in vertical accuracy of UAV-based DSMs was observed when GCPs were used.
\end{abstract}

Keywords: stereo photogrammetry, unmanned aerial vehicle (UAV), digital surface model (DSM), Structure from Motion (SfM), light detection and ranging (LiDAR), vertical agreement assessment, forest inventory

\section{INTRODUCTION}

Today we are witnessing the growing use of unmanned aerial vehicles (UAVs) for monitoring purposes. Potential applications of UAVs can be found in agricultural, forestry, and environmental sciences; surveillance, and reconnaissance; aerial monitoring in engineering; cultural heritage; and traditional surveying, conventional mapping and photogrammetry, and cadastral applications [1]. Due to various construction solutions UAVs are flexibile to solve various surveying tasks. Compared to the classical terrestrial survey, UAVs are capable to cover considerably larger areas in short time period, as well as to survey distant or inaccessible areas (e.g. distant forest and mined areas) and objects (e.g. high buildings). The flexibility of photogrammetric surveying methods along with the selection of the adequate cameras and lenses results in adaption of the measuring platform (UAV) to the needs 
of the tasks. Furthermore, UAVs have a capability of an autonomous recording, and hence they are becoming independent devices for gathering a large number of highquality data of the field or object with appropriate accuracy.

Recently, comprehensive reviews on applications of UAVs in forestry have been provided by Tang and Shao [2] and Torresan et al. [3]. In general, the common UAVs applications in forestry are related to monitoring of forest health and disturbances [4-6], forest inventory [7, 8], forest cover mapping [9], etc. Digital surface model (DSM), which is one of the main photogrammetric products of UAV surveys, has great application in forest inventory. By subtracting available digital terrain model (DTM), which presents terrain surface, from DSM, which presents forest surface, a canopy height model (CHM) is generated. DTMs are nowadays commonly generated using airborne laser scanning (ALS) technology based on light detection and ranging (LiDAR) or airborne digital photogrammetry [10]. From CHMs various metrics can be derived which are then used for estimation of various tree [11] and stand variables $[7,12]$. The Structure from Motion (SfM) algorithm has been suggested for DSM generation by many authors [13-15]. Camera calibration and image phototriangulation process are initially performed to generate accurate DSM or digital terrain model (DTM) [16]. Camera calibration method and the algorithm for the precise elimination of lens distortion on digital cameras was developed by Gašparović and Gajski [17]. Continuing the research Gašparović and Gajski [18] presented a new method of two-step camera calibration for micro UAVs.

Methods for producing photogrammetric DSMs without using ground control points (GCPs) were presented in several studies [19-21]. To obtain external orientation parameters, Chikhradze [19] used single-frequency Global Navigation Satellite Systems (GNSS) receivers, while Vander et al. [20] and Fazeli et al. [21] used dual-frequency differential GNSS. Furthermore, Gimbal influence on the stability of exterior orientation parameters of UAV images was examined in study by Gašparović and Jurjević [22].
The DSMs generated from airborne digital stereo images were evaluated in many studies [e.g. 23-25] which revealed that many factors may influence on their quality, especially in complex forest structure. The research on DSM quality obtained from UAV images are still lacking (especially in South-east European region), but it can be assumed that apart from technical characteristics related to UAV (e.g. camera quality, GNSS precision) similar factors (e.g. image quality, algorithm for image processing, weather conditions, forest structure, etc.) are present.

The main goal of this research is to evaluate the quality of photogrammetry-based DSM from low-cost UAV's images collected in non-optimal weather (windy and cloudy weather) and environmental (inaccessibility for regular spatial distribution of GCPs) conditions. Namely, urgent cases (e.g. detection and estimation of forest damage) sometimes require rapid and immediate reaction when data acquisitions have to be done in non-optimal weather conditions during the survey. Furthermore, in dense forests it is very difficult to find a place for GCPs, especially to obtain the regular spatial distribution of GCPs which will provide the most accurate orientation of images. Therefore, vertical agreement assessment of UAV-based DSMs generated without and with using GCPs was evaluated with LiDARbased DSM in this study.

\section{MATERIALS AND METHODS}

\section{Study Area}

The research was conducted in the lowland forest complex of Pokupsko Basin located $35 \mathrm{~km}$ southwest of Zagreb, Central Croatia (Figure 1). The study area (77.39 ha) encompasses two 45-year-old mixed forest stands (subcompartments $36 \mathrm{a}$ and $37 \mathrm{a}$, management unit "Jastrebarski lugovi") dominated by pedunculate oak (Quercus robur L.) accompanied by black alder (Alnus glutinosa (L.) Geartn.), common hornbeam (Carpinus betulus L.), and narrow-leaved ash (Fraxinus angustifolia

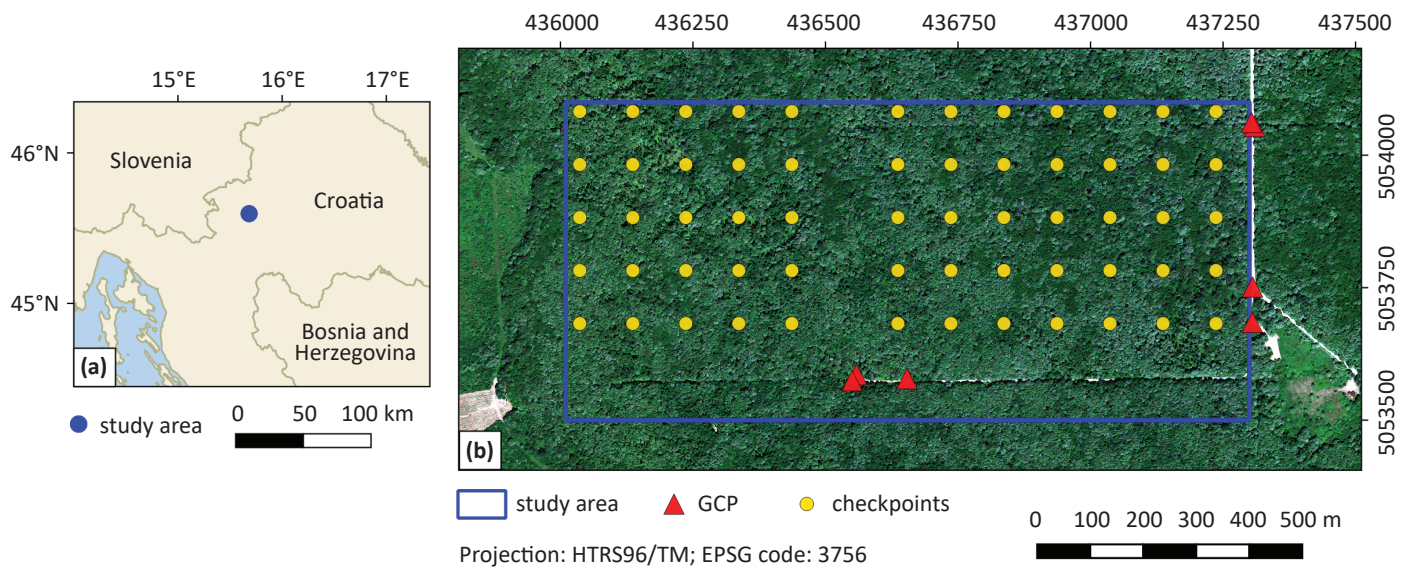

FIGURE 1. (a) Location of the study area; (b) Study area with 7 GCPs and 60 checkpoints of the regular $100 \mathrm{~m}$ sampling grid (background: satellite image WorldView-3, "true colour" composite (5-3-2), sensing date: 12 June 2017). 
Vahl.), and with the Corylus avellana L. and Crataegus monogyna Jacq. in the understorey. The study area is flat, with ground elevations ranging from 108 to $113 \mathrm{~m}$ a.s.l.

\section{UAV-Based Canopy Digital Surface Models}

The UAV images were acquired using the DJI Phantom 4 Pro UAV with FC6310 camera (Table 1) on 14 September 2017. The average flying height was $200 \mathrm{~m}$ above ground level. The study area was covered by 488 RGB images with the ground sampling distance (GSD) of approximately $5 \mathrm{~cm}$. The images were collected in 11 flight lines with endlap of $90 \%$ and sidelap of $80 \%$. Weather conditions during UAV survey were not suitable (non-optimal) due to windy and cloudy weather.

TABLE 1. Characteristics of FC6310 camera.

\begin{tabular}{cc}
\hline Digital camera & FC6310 \\
\hline Sensor type & CMOS \\
Sensor size $(\mathrm{mm})$ & $13.2 \times 8.8$ \\
Pixels size on the sensor $(\mu \mathrm{m})$ & 2.4 \\
Number of pixels (million) & 20 \\
Sensor sensitivity & $100-12800$ \\
Max. aperture & F2.8 \\
Field of view ( ${ }^{\circ}$ ) & 84 \\
Image size (pixels) & $5472 \times 3078$ \\
Focal length $(\mathrm{mm})$ & 8.8 \\
\hline
\end{tabular}

Before the UAV survey, seven ground control points (GCPs) were placed and measured in the study area (Figure 1). The GCPs' positions ( $x, y, z$ coordinates) were measured using the Trimble GNSS receiver connected with the Croatian Positioning System (CROPOS) which enables to obtain both horizontal and vertical positional accuracy from 2 to $5 \mathrm{~cm}$ (CROPOS - Users' Manual). Due to dense forest and mostly invisible ground from the air, it was not possible to provide (set up) the regular spatial distribution of GCPs over the entire study area which enables the most accurate orientation of images [26]. Therefore, GCPs were set up and measured on the forest roads from where they can be easily detected on UAV images (Figure 1).

From the collected UAV images, two DSMs were generated. First DSM was generated without using GCPs. This means that DSM was generated from UAV images whose orientation was based on a priori exterior orientation parameters (EOPs) only. A priori EOPs were measured during flight in metadata files of each image by GNSS. Firstly, tie-points on all images were automatically determined using the Structure from Motion (SfM) algorithm. Image coordinates of tie-points and a priori EOPs were then used for photo-triangulation with self-calibration. By automatic correlation of oriented images, the point cloud was obtained and then used to generate raster DSM (hereinafter referred to as $D_{S M}$ ) with a spatial resolution of $0.5 \mathrm{~m}$.

To generate the second DSM, the classic image phototriangulation method based on tie-points and GCPs was used. Tie-points on all images, as in the previous case, were automatically determined using SfM algorithm. Phototriangulation with self-calibration was based on image coordinates of tie-points and GCPs, and GCPs' coordinates in the terrestrial coordinate system. $A$ priori EOPs were not used in this case. A raster DSM (hereinafter referred to as $\mathrm{DSM}_{\mathrm{P}-\mathrm{GCP}}$ ) with a spatial resolution of $0.5 \mathrm{~m}$ was generated from the point cloud obtained by automatic correlation of oriented images.

The whole procedure of image orientation and DSMs generation was performed using Agisoft PhotoScan software (version 1.2.6, 64 bit).

\section{LiDAR-Based Canopy Digital Surface Model}

A raster LiDAR-based DSM (hereinafter referred to as $\mathrm{DSM}_{\mathrm{L}}$ ) with a spatial resolution of $0.5 \mathrm{~m}$ was provided by Hrvatske vode Ltd. (Zagreb, Croatia). Table 2 provides an overview of LiDAR sensor and data characteristics used for DSM generation. The resulting point densities (11.59 points $\left.\cdot \mathrm{m}^{-2}\right)$ and the stated horizontal $(0.15 \mathrm{~m})$ and vertical (0.08 $\mathrm{m}$ ) accuracies were based on a considerably larger area (which included and non-forested areas as well) than the one considered in this study. DSM $\mathrm{L}_{\mathrm{L}}$ was generated from returns classified as "first return" and "only return". $D_{S M}$ was used as reference data for vertical agreement assessment of UAV-based DSMs (DSM p $_{\mathrm{p}}$ and DSM ${ }_{\mathrm{P}-\mathrm{GCP}}$ ). Due to its high accuracy, the LiDAR data were often used as reference data for evaluation of UAV data [27-29].

TABLE 2. LIDAR sensor and data characteristics.

\begin{tabular}{cc}
\hline Parameter & Technical specification \\
\hline Platform & Pilatus P6 aircraft \\
Sensor & Optech ALTM Gemini 167 \\
Flying period & 29 June -25 August 2016 \\
Flying height above ground level $(\mathrm{m})$ & 720 \\
Flying speed $\left(\mathrm{m} \cdot \mathrm{s}^{-1}\right)$ & 51 \\
Pulse repetition frequency $(\mathrm{kHz})$ & 125 \\
Scan frequency $(\mathrm{Hz})$ & 40 \\
Field of view $\left({ }^{\circ}\right)$ & \pm 25 \\
Swath width $(\mathrm{m})$ & 671 \\
Max No. of returns per pulse & 4 \\
Point density (points $\left.\cdot \mathrm{m}^{-2}\right)$ & 11.59 \\
Horizontal accuracy $(\mathrm{m})$ & 0.15 \\
Vertical accuracy $(\mathrm{m})$ & 0.08 \\
\hline
\end{tabular}

\section{Vertical Agreement Assessment}

The vertical agreement assessment of the UAVbased DSMs was conducted by comparing elevations of 60 checkpoints of a regular $100 \mathrm{~m}$ grid obtained from $\mathrm{DSM}_{\mathrm{L}}$ with the elevations of planimetrically corresponding

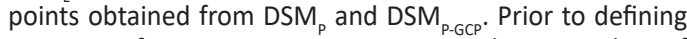
measures for agreement assessment, the normality of residuals (vertical errors between UAV- and LiDAR-based DSMs) distribution was analyzed using: (a) histograms with 
a superimposed curve indicating normal distribution, (b) Shapiro-Wilk test [30, 31], and (c) normal Q-Q plots (Figure 2). All performed tests revealed non-normal distribution of vertical errors for both UAV-based DSMs. Consequently, the following robust measures suggested by Höhle and Höhle [10] were used for vertical agreement assessment: median, normalised median absolute deviation (NMAD), $68.3 \%$ quantile and $95 \%$ quantile. Additionally, root mean square errors before (RMSE) and after removing outliers (RMSE*) were calculated. The equations for all measures, as well as for the threshold for outliers can be found in Höhle and Höhle [10]. The statistical analyses were performed using the STATISTICA software (version 11) [32] and $R$ programming language (version 3.3.3) [33].

To support statistical analyses, the visual assessment of UAV- and LiDAR-based DSMs, as well as the visual assessment of difference raster models was performed. Difference raster models were generated by subtracting LiDAR-based from UAV-based DSMs. Both, difference raster model generation and its visualization were conducted using Global Mapper (version 19) [34] and QGIS (version 2.18) [35] software.

\section{RESULTS AND DISCUSSION}

According to the described methods, DSM $_{p}$ (Figure

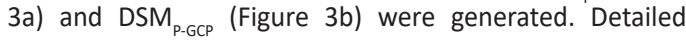

information on DSMs processing is presented in Table 3. It can be seen that computer processing time for both DSMs is almost the same, whereas the time spent on manual work is considerably greater for DSM P-GCP $_{\text {gention (30 }}$ $\mathrm{min}$ ) than for DSM generation (10 min). Namely, during the DSM $_{\text {P-GCP }}$ generation, most of the time ( $\approx 20 \mathrm{~min}$ ) was spent on the manual detection of the GCPs on images, while for the DSM generation the UAV images were orientated without using GCPs.

The results of the vertical agreement assessment of the UAV-based DSMs (DSM $M_{P}$ and DSM ${ }_{P-G C P}$ ) with DSM conducted on 60 checkpoints of the regular $100 \mathrm{~m}$ sample grid are shown in Table 4 . When comparing UAV-based DSMs with $D M_{L}$, it is necessary to have in mind that between the acquisition of LiDAR and UAV data is a time gap of one year which corresponds with one vegetation and subsequently with annual height increment. According to the internal database (unpublished material) of Croatian Forest Research Institute, annual height increment for the forest of the study area ranges from $0.2 \mathrm{~m}$ to $0.45 \mathrm{~m}$ depending on tree species. As expected, DSM ${ }_{\text {P-GCP }}$ shows higher accuracy, i.e. higher vertical agreement with DSM, than $\mathrm{DSM}_{\mathrm{p}}$. Namely, the horizontal accuracy $\left(\mathrm{RMSE}_{\mathrm{xY}}\right)$ of $\mathrm{DSM}_{\mathrm{p}}$ assessed with $7 \mathrm{GCPs}$ (which were not used in its generation) is $5.67 \mathrm{~m}$ (Table 3). Since such horizontal errors may produce greater vertical errors [36], especially for surfaces with great variations in height on a small area (e.g. forest) $[25,37]$, the lower vertical agreement of $D_{S M}$ with a) Histogram (DSM - DSM $\left._{L}\right)$

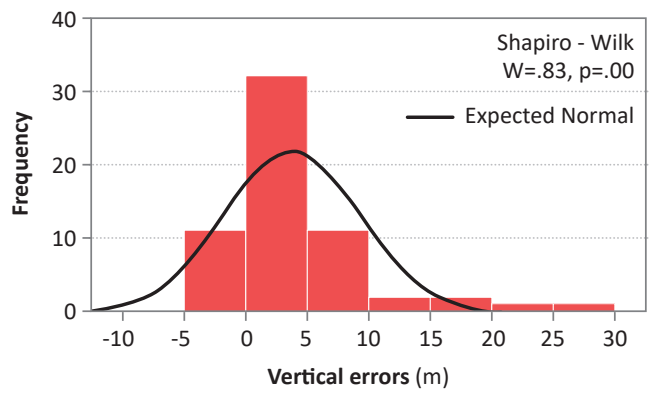

c) Normal Q-Q plot (DSM - DSM $\left._{\mathrm{L}}\right)$

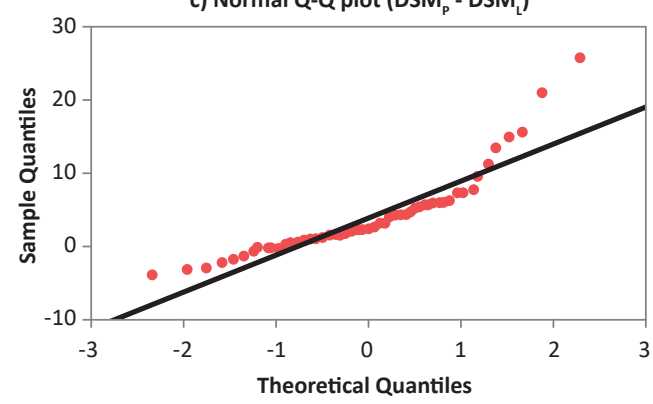

b) Histogram (DSM P.GCP $\left._{-}-D_{\text {SM }}\right)$

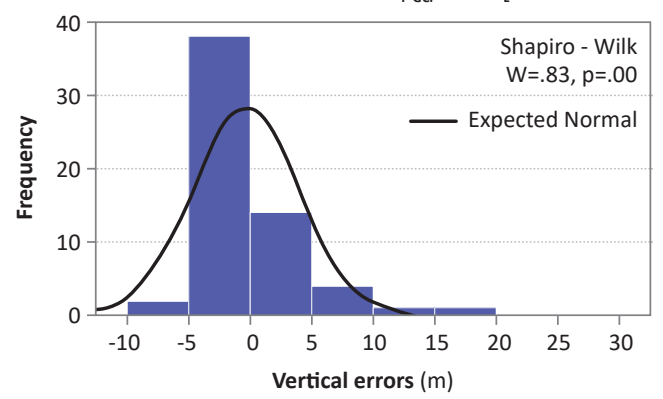

d) Normal Q-Q plot (DSM $\left.{ }_{P-G C P}-D^{-} M_{L}\right)$

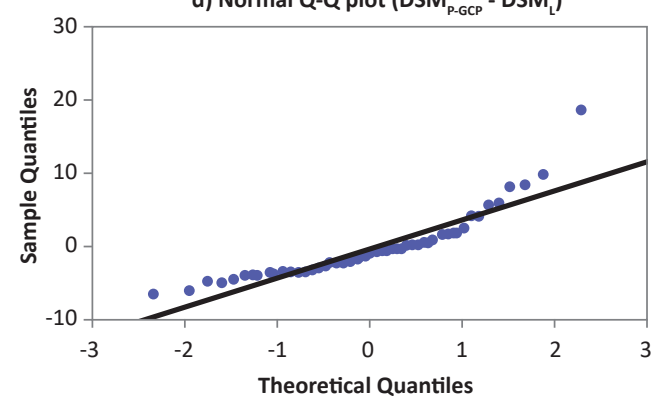

FIGURE 2. Normality test of residuals (vertical errors between UAV- and LiDAR-based DSMs): (a) and (b) histograms with a superimposed curve indicating normal distribution with accompanied results of the Shapiro-Wilk test; (c) and (d) indicate normal Q-Q plots. 
TABLE 3. Information on UAV image orientation and DSMs processing.

\begin{tabular}{|c|c|c|}
\hline Model & DSM $_{p}$ & DSM $_{\text {P.GCP }}$ \\
\hline Number of images & 488 & 488 \\
\hline Number of GCPs & 0 & 7 \\
\hline $\mathrm{GSD}(\mathrm{cm})$ & 5.26 & 5.27 \\
\hline Coverage area (ha) & 121 & 122 \\
\hline Images with EOP & 474 & 474 \\
\hline Number of tie points & 353,025 & 352,530 \\
\hline Reprojection error (pixels) & 0.874 & 0.885 \\
\hline $\operatorname{RMSE}_{\mathrm{XY}}(\mathrm{m})$ & 5.686 & 0.161 \\
\hline $\mathrm{RMSE}_{z}(\mathrm{~m})$ & 8.194 & 0.059 \\
\hline $\operatorname{RMSE}_{\mathrm{XYZ}}(\mathrm{m})$ & 9.974 & 0.171 \\
\hline Number of point cloud points & $2,487,740$ & $2,389,107$ \\
\hline DSM resolution $(\mathrm{m})$ & $0.5 \times 0.5$ & $0.5 \times 0.5$ \\
\hline Processing time: computer + manual (min) & $88+10$ & $89+30$ \\
\hline
\end{tabular}

GCP - ground control point; GSD - ground sample distance; EOP - exterior orientation parameters; RMSE $_{\mathrm{XY}}$ - root mean square error (horizontal); $\mathrm{RMSE}_{\mathrm{z}}$ - root mean square error (vertical); $\mathrm{RMSE}_{\mathrm{XYZ}}$ - root mean square error (overall)

$D_{S M}$ is understandable. This is especially evident in Figure 3c, which shows a comparison of DSMs' profiles through the exemplary area. By observing profiles at greater peaks, it can be seen that DSM ${ }_{\text {P.GCP }}$ profile follows the DSM $M_{L}$ profile, whereas for DSM profile the horizontal displacement of 5-10 m compared to DSM profile can be observed. The improvement in vertical agreement of UAV-based DSMs with DSM $\mathrm{L}_{\mathrm{L}}$ when GCPs are used can be observed visually on difference models (Figure 4). Similarly, when comparing two DSMs derived from WorldView-2 images, Hobi and Ginzler [38] found clear improvement of the DSM's vertical accuracy when GCPs were used.

Furthermore, Figure $3 c$ shows that DSM provides the highest discrimination of vertical forest structure clearly describing very steep variations in height (e.g. small gaps in

TABLE 4. The vertical agreement assessment of the UAVbased DSMs with LiDAR-based DSM.

\begin{tabular}{ccc}
\hline Agreement measure & DSM $_{\mathrm{p}}$ & DSM $_{\text {p-GCP }}$ \\
\hline Median $(\mathrm{m})$ & 2.23 & -1.33 \\
$\operatorname{NMAD}(\mathrm{m})$ & 3.22 & 2.77 \\
$68.3 \%$ quantile $(\mathrm{m})$ & 4.34 & 0.11 \\
$95 \%$ quantile $(\mathrm{m})$ & 15.04 & 8.15 \\
RMSE $(\mathrm{m})$ & 6.61 & 4.26 \\
$\mathrm{~N}_{\text {outliers }}$ & 2 & 1 \\
RMSE* $^{(m)}$ & 5.10 & 3.54
\end{tabular}

NMAD - normalised median absolute deviation; RMSE - root mean square error; $\mathrm{N}_{\text {outliers }}$ - number of outliers; RMSE* - root mean square error without outliers the forest canopy, forest road). On the contrary, the profiles of both UAV-based DSMs are considerably smoother. Only bigger gaps in the forest canopy and a forest road (Figure $3 \mathrm{a}$ and $3 \mathrm{~b}$ ) can be detected, but in both cases, the vertical profiles of UAV-based DSMs do not reach the ground elevations. This is reasonable because LiDAR is an active sensor whose beams can penetrate through smaller gaps in the forest canopy and reach the ground, whereas the digital camera of UAV system used in this research (Table 1) is a passive optical sensor whose signal can characterize only the canopy surface [39].

Besides the technical limitations of low-cost UAV (e.g. camera quality, GNSS precision) used in this study and nonregular spatial distribution of GCPs, it can be suggested that the weather conditions (windy and cloudy weather) during UAV survey influenced image quality to a certain extent and consequently DSMs quality. The uncertainties are larger due to the complexity of the forest environment (e.g. moving trees, occlusions, shadows, images radiometric quality, etc.), which seriously affect the image matching procedure, and thus DSM quality $[23,25,40,41]$.

\section{CONCLUSIONS}

This research confirmed great potential of images obtained by low-cost UAV for forestry applications, even if they are surveyed in non-optimal weather (windy and cloudy weather) and environmental (inaccessibility for regular spatial distribution of GCPs) conditions. This could be of importance for cases when urgent UAV surveys are needed (e.g. detection and estimation of forest damage) which do not allow careful and longer survey planning. 

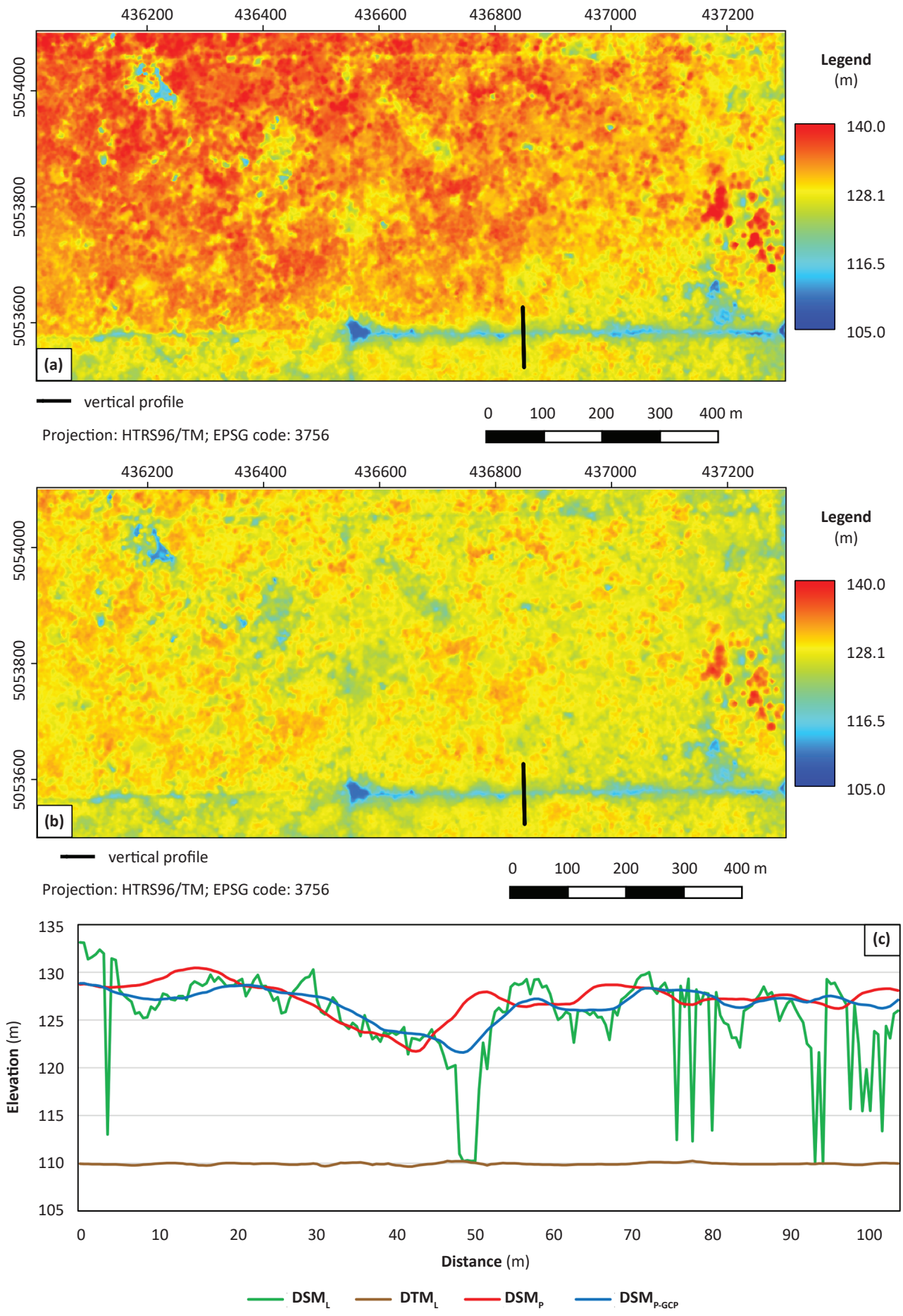

FIGURE 3. (a) UAV-based digital surface model generated without using GCPs (DSM $)$; (b) UAV-based digital surface model

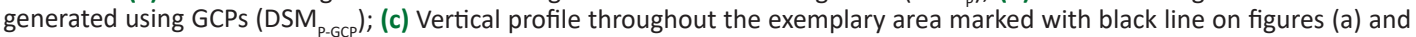
(b) $\left(D_{S M}\right.$ - LiDAR-based digital surface model; DTM - LiDAR-based digital terrain model). 

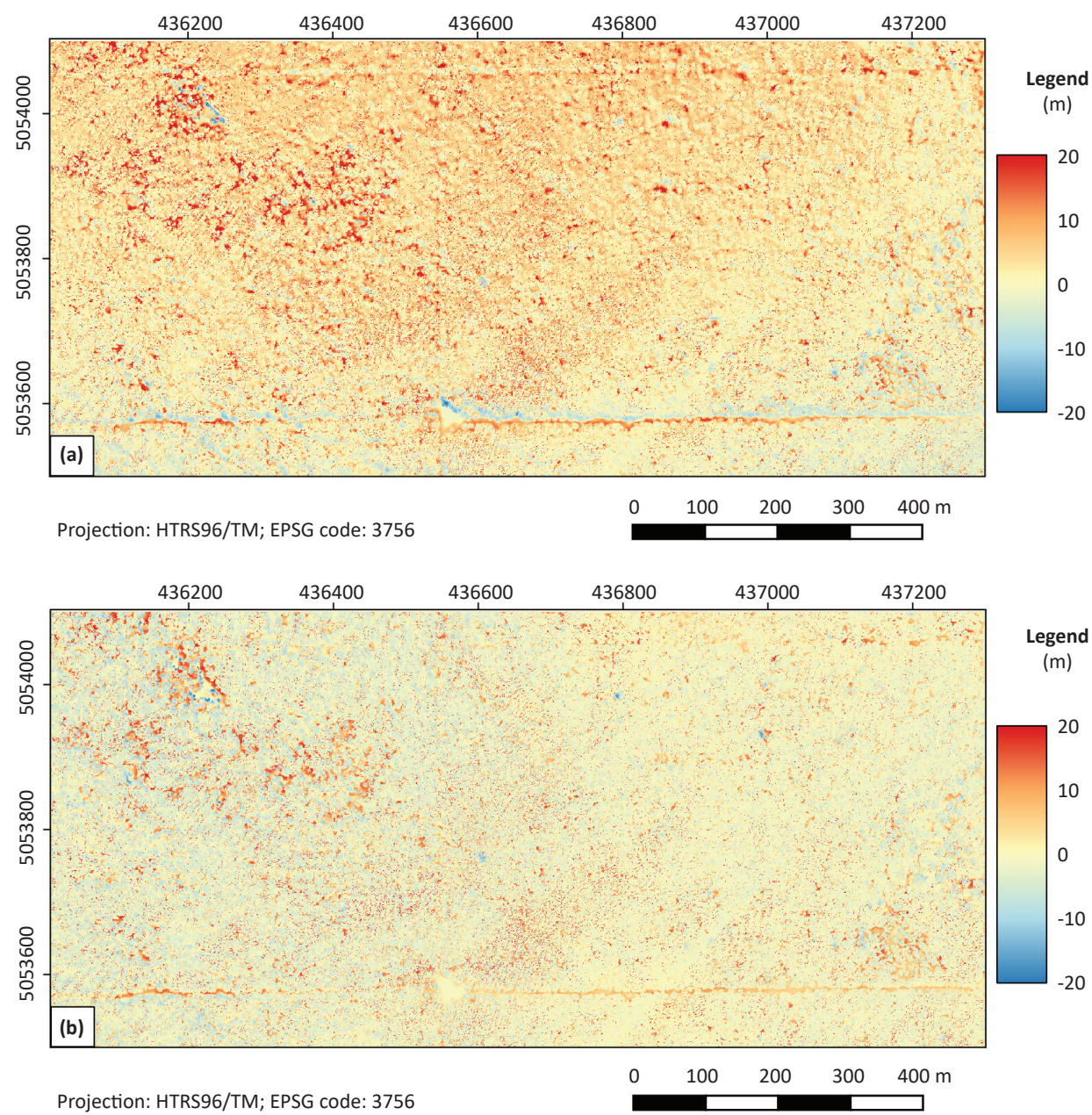

FIGURE 4. (a) Difference model generated by subtracting $\mathrm{DSM}_{\mathrm{L}}$ from $\mathrm{DSM}_{\mathrm{p}}$; (b) Difference model generated by subtracting DSM from DSM $M_{P-G C P}$.

The vertical agreement assessment of UAV-based DSMs with LiDAR-based DSM confirmed the importance of GCPs for image orientation and DSM generation. Namely, a considerable improvement in vertical accuracy of UAVbased DSMs was observed when GCPs were used. While DSMs generated without GCPs can be used for visualisation and monitoring purposes, DSMs generated with GCPs have potential to be used in forest inventory. To confirm this, further research should focus on estimating the accuracy of tree and stand attributes.

\section{Acknowledgments}

This research has been supported by the Croatian Science Foundation under the projects IP-2016-06-7686 "Retrieval of Information from Different Optical 3D Remote Sensing Sources for Use in Forest Inventory (3D-FORINVENT)" and IP-2016-065621 "Geospatial Monitoring of Green Infrastructure by Means of Terrestrial, Airborne and Satellite Imagery (GEMINI)". The authors wish to thank Hrvatske vode, Zagreb, Croatia, for providing ALS data.

\section{REFERENCES}

1. COLOMINA I, MOLINA P 2014 Unmanned aerial systems for photogrammetry and remote sensing: A review. ISPRS J Photogramm Remote Sens 92: 79-97. DOI: https://doi. org/10.1016/i.isprsiprs.2014.02.013
2. TANG L, SHAO G 2015 Drone remote sensing for forestry research and practices. J For Res 26 (4): 791-797. DOI: https://doi.org/10.1007/s11676-015-0088-y 
3. TORRESAN C, BERTON A., CAROTENUTO F, DI GENNARO SF, GIOLI B, MATESE A, MIGLIETTA F, VAGNOLI, C, ZALDEI A, WALLACE L 2017 Forestry applications of UAVs in Europe: a review. Int J Remote Sens 38 (8-10): 2427-2447. DOI: https://doi.org/10.1080/01431161.2016.1252477

4. NÄSI $R$, HONKAVAARA $E$, LYYTIKÄINEN-SAARENMAA $P$, BLOMQVIST M, LITKEY P, HAKALA T, VILJANEN N, KANTOLA T, TANHUANPÄÄ T, HOLOPAINEN M 2015 Using UAV-based photogrammetry and hyperspectral imaging for mapping bark beetle damage at tree-level. Remote Sens 7 (11): 15467-15493. DOI: https://doi.org/10.3390/rs71115467

5. SMIGAJ M, GAULTON R, BARR SL, SUÁREZ JC 2015 UAVborne thermal imaging for forest health monitoring: detection of disease-induced canopy temperature increase. ISPRS - Int Arch Photogramm Remote Sens Spat Inf Sci XL-3/W3: 349-354. DOI: https://doi.org/10.5194/ isprsarchives-XL-3-W3-349-2015

6. DASH JP, WATT MS, PEARSE GD, HEAPHY $M$, DUNGEY HS 2017 Assessing very high resolution UAV imagery for monitoring forest health during a simulated disease outbreak. ISPRS J Photogramm 131: 1-14. DOI: https://doi. org/10.1016/i.isprsjprs.2017.07.007

7. PULITI S, ØRKA HO, GOBAKKEN T, NÆESSET E 2015 Inventory of Small Forest Areas Using an Unmanned Aerial System. Remote Sens 7 (8): 9632-9654. DOI: https://doi. org $/ 10.3390 /$ rs70809632

8. KACHAMBA DJ, ØRKA HO, GOBAKKEN T, EID T, MWASE W 2016 Biomass Estimation Using 3D Data from Unmanned Aerial Vehicle Imagery in a Tropical Woodland. Remote Sens 8 (11): 968. DOI: https://doi.org/10.3390/rs8110968

9. GETZIN S, NUSKE RS, WIEGAND K 2014 Using Unmanned Aerial Vehicles (UAV) to Quantify Spatial Gap Patterns in Forests. Remote Sens 6 (8): 6988-7004. DOI: https://doi. org $/ 10.3390 / \mathrm{rs} 6086988$

10. HÖHLE J, HÖHLE M 2009 Accuracy assessment of digital elevation models by means of robust statistical methods. ISPRS J Photogramm 64 (5): 398-406. DOI: https://doi. org/10.1016/i.isprsiprs.2009.02.003

11. GUERRA-HERNÁNDEZ J, GONZÁLEZ-FERREIRO E, SARMENTO A, SILVA J, NUNES A, CORREIA AC, FONTES L, TOMÉ M, DÍAZ-VARELA R 2016 Using high resolution UAV imagery to estimate tree variables in Pinus pinea plantation in Portugal. Forest Syst 25 (2): eSC09. DOI: https://doi. org/10.5424/fs/2016252-08895

12. TUOMINEN S, BALAZS A, SAARI H, PÖLÖNEN I, SARKEALA J, VIITALA R 2015 Unmanned aerial system imagery and photogrammetric canopy height data in area-based estimation of forest variables. Silva Fenn 49 (5): 1348. DOI: https://doi.org/10.14214/sf.1348

13. WALLACE L, LUCIEER A, MALENOVSKỲ Z, TURNER $D$, VOPĚNKA P 2016 Assessment of forest structure using two UAV techniques: A comparison of airborne laser scanning and structure from motion (SFM) point clouds. Forests 7 (3): 62. DOI: https://doi.org/10.3390/f7030062

14. HIRD JN, MONTAGHI A, MCDERMID GJ, KARIYEVA J, MOORMAN BJ, NIELSEN SE, MCINTOSH A 2017 Use of unmanned aerial vehicles for monitoring recovery of forest vegetation on petroleum well sites. Remote Sens 9 (5): 413. DOI: https://doi.org/10.3390/rs9050413

15. MLAMBO R, WOODHOUSE IH, GERARD F, ANDERSON $K$ 2017 Structure from motion (SFM) photogrammetry with drone data: A low cost method for monitoring greenhouse gas emissions from forests in developing countries. Forests 8 (3): 68. DOI: https://doi.org/10.3390/f8030068

16. NEX F, REMONDINO F 2014 UAV for 3D mapping applications: A review. Appl Geomatics 6 (1): 1-15. DOI: https://doi.org/10.1007/s12518-013-0120-x
17. GAŠPAROVIĆ M, GAJSKI D 2016 The algorithm for the precise elimination of lens distortion influence on digital cameras. Geod List 70 (1): 25-38. URL: http://hrcak.srce.

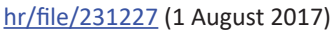

18. GAŠPAROVIĆ M, GAJSKI D 2016 Two-step camera calibration method developed for micro UAV'S. ISPRS Int Arch Photogramm Remote Sens Spat Inf Sci XLI-B1: 829-833. DOI: https://doi.org/10.5194/isprsarchivesXLI-B1-829-2016

19. CHIKHRADZE N 2015 Close Range Photogrammetry in the Survey of the Coastal Area Geoecological Conditions (on the Example of Portugal). Earth Sci 4 (5): 35. DOI: https:// doi.org/10.11648/i.earth.s.2015040501.17

20. VANDER JAGT B, LUCIEER A, WALLACE L, TURNER D, DURAND M 2015 Snow Depth Retrieval with UAS Using Photogrammetric Techniques. Geosci 5 (3): 264-285. DOI: https://doi.org/10.3390/geosciences5030264

21. FAZELI H, SAMADZADEGAN F, DADRASJAVAN F 2016 Evaluating the potential of RTK-UAV for automatic point cloud generation in 3D rapid mapping. ISPRS - Int Arch Photogramm Remote Sens Spat Inf Sci XLI-B6: 221-226. DOI: https://doi.org/10.5194/isprsarchives-XLI-B6-221-2016

22. GAŠPAROVIĆ M, JURJEVIĆ L 2017 Gimbal Influence on the Stability of Exterior Orientation Parameters of UAV Acquired Images. Sensors 17 (2): 401. DOI: https://doi. org/10.3390/s17020401

23. BALTSAVIAS E, GRUEN A, EISENBEISS H, ZHANG L, WASERL T 2008 High-quality image matching and automated generation of 3D tree models. Int J Remote Sens 29 (5): 12431259. DOI: https://doi.org/10.1080/01431160701736513

24. ST-ONGE B, VÉGA C, FOURNIER RA, HU Y 2008 Mapping canopy height using a combination of digital stereophotogrammetry and lidar. Int J Remote Sens 29 (11): 33433364. DOI: https://doi.org/10.1080/01431160701469040

25. BALENOVIĆ I, MARJANOVIĆ H, VULETIĆ D, PALADINIĆ E, OSTROGOVIĆ SEVER MZ, INDIR K 2016 Quality assessment of high density digital surface model over different land cover classes. Period Biol 117 (4): 1-12. DOI: https://doi. org/10.18054/pb.2015.117.4.3452

26. REHAK M 2017 Integrated Sensor Orientation on Micro Aerial Vehicles. Phd Thesis, Swiss Federal Institute of Technology Lausanne (EPFL), Lausanne, Switzerland, 227 p. DOI: https://doi.org/10.5075/epfl-thesis-7530

27. NI W, LIU J, ZHANG Z, SUN G, YANG A 2015 Evaluation of UAV-based forest inventory system compared with LiDAR data. IGARSS 2015: 3874-3877. DOI: https://doi. org/10.1109/IGARSS.2015.7326670

28. VEPAKOMMA U, CORMIER D 2015 Inventorying the forest: Laser scanning vs close range photogrammetry on a UAV. In 14th conference in a series focusing on Lidar Applications for assessing and Managing Forest Ecosystems-SilviLaser, France, La Grande Motte, 28-30 September 2015. The French Society of Photogrammetry and Remote Sensing (SFPT), Paris, France, pp 68-70. URL: https://silvilaser2015.teledetection.fr/files/Proceedings Silvilaser 22092015 2.pdf (21 August 2017)

29. THIEL C, SCHMULLIUS C 2017 Comparison of UAV photograph-based and airborne lidar-based point clouds over forest from a forestry application perspective. Int J Remote Sens 38 (8-10): 2411-2426. DOI: https://doi.org/10 $.1080 / 01431161.2016 .1225181$

30. SHAPIRO SS, WILK MB 1965 An analysis of variance test for normality (complete samples). Biometrika 52 (3-4): 591611. DOI: https://doi.org/10.1093/biomet/52.3-4.591

31. SHAPIRO SS, WILK MB, CHEN HJ 1968 A comparative study of various tests for normality. J Am Stat Assoc 63 (324): 1343-1372. DOI: https://doi.org/10.1080/01621459.1968 .10480932 
32. HILL T, LEWICKI P 2007 STATISTICS: Methods and Applications. StatSoft, Inc., Tulsa, OK, USA, $800 p$

33. R CORE TEAM 2017 R: A language and environment for statistical computing. R Foundation for Statistical Computing, Vienna, Austria. URL: https://www.R-project. org/ (3 September 2017)

34. BLUE MARBLE GEOGRAPHICS 2017 Global Mapper 19. URL: http://www.bluemarblegeo.com/products/globalmapper.php (4 September 2017)

35. QGIS DEVELOPMENT TEAM 2017 QGIS Geographic Information System. Open Source Geospatial Foundation. URL: http://qgis.osgeo.org (14 September 2017)

36. HÖHLE J, PEDERSEN C $\varnothing$, BAYER T, FREDERIKSEN P 2010 The photogrammetric derivation of digital terrain models in built-up areas. Photogrammetric Journal of Finland 22 (1): $33-45$

37. NURMINEN K, KARJALAINEN $M$, YU $X$, HYYPPÄ J, HONKAVAARA E 2013 Performance of dense digital surface models based on image matching in the estimation of plotlevel forest variables. ISPRS J Photogramm 83: 104-115. DOI: https://doi.org/10.1016/j.isprsjprs.2013.06.005
38. HOBI ML, GINZLER C 2012 Accuracy Assessment of Digital Surface Models Based on WorldView-2 and ADS80 Stereo Remote Sensing Data. Sensors 12 (5): 6347-6368. DOI: https://doi.org/10.3390/s120506347

39. WHITE JC, STEPPER C, TOMPALSKI P, COOPS NC, WULDER MA 2015 Comparing ALS and Image-Based Point Cloud Metrics and Modelled Forest Inventory Attributes in a Complex Coastal Forest Environment. Forests 6 (10): 37043732. DOI: https://doi.org/10.3390/f6103704

40. VALBUENA R, MAURO F, ARJONILLA FJ, MANZANERA JA 2011 Comparing airborne laser scanning-imagery fusion methods based on geometric accuracy in forested areas. Remote Sens Environ 115 (8): 1942-1954. DOI: https://doi. org/10.1016/i.rse.2011.03.017

41. SIMIC MILAS A, AREND K, MAYER C, SIMONSON MA, MACKEY S 2017 Different Colors of Shadows: Classification of UAV images. Int J Remote Sens 38 (8-10): 3084-3100. DOI: https://doi.org/10.1080/01431161.2016.1274449 